\title{
PARAMETER KINETIKA REAKSI DEKOMPOSISI KATALITIK METANA MENJADI KARBON NANOTUBE DENGAN KATALIS Ni-Cu-Al
}

\author{
Praswasti PDK Wulan, Widodo W Purwanto*, Yuswan Muharam, \\ Anindya Adiwardhana \\ Departemen Teknik Kimia, Fakultas Teknik, Universitas Indonesia \\ Kampus Baru UI, Depok 16424 \\ Email: widodo@che.ui.ac.id, wulan@che.ui.ac.id
}

\begin{abstract}
Abstrak
Pengembangan teknologi produksi karbon nanotube melalui konversi katalitik hidrokarbon akan efisien dan efektif jika didasarkan pada pengetahuan mekanisme nukleasi dan pertumbuhan karbon nanotube. Sebagian besar studi melakukan riset yang difokuskan pada identifikasi produk utama reaksi dan estimasi energi aktivasi. Data kinetika dan mekanisme pertumbuhan karbon nanotube tidak tersedia dengan lengkap sehingga model kinetika proses selalu didasarkan pada data kinetika eksperimen. Pada penelitian ini, dilakukan studi untuk memperoleh parameter kinetika reaksi dekomposisi katalitik metana menggunakan katalis $\mathrm{Ni}-\mathrm{Cu}-\mathrm{Al}$ dengan target komposisi 2:1:1 yang dipreparasi dengan metode kopresipitasi menggunakan presipitan larutan natrium karbonat. Data kinetika eksperimen diambil pada rentang temperatur $650-750{ }^{\circ} \mathrm{C}$ dan tekanan 1 atmosfer. Data kinetika diuji dengan model kinetika mikro yang diturunkan dari mekanisme reaksi permukaan katalis. Model kinetika yang paling sesuai dengan hasil percobaan adalah tahap adsorpsi yang menunjukkan bahwa konsumsi intermediate (reaksi permukaan) lebih cepat dari pembentukan intermediate (adsorpsi metana). Parameter kinetika yang diperoleh berupa Energi aktivasi sebesar 40,6 kJ/mol dan faktor pre-eksponensial 8,625 x 106.
\end{abstract}

Kata-kata kunci: dekomposisi metana; hidrogen; karbon nanotube; kopresipitasi, kinetika reaksi

\begin{abstract}
Development of production technology of nanotubes carbon through catalytic conversion of hydrocarbons will be efficient and effective if based on knowledge of the nucleation and growth mechanism of carbon nanotubes. Most of the research that focused on identifying the main products of reaction and estimate the activation energy. Growth kinetics and mechanism data of carbon nanotubes not completely available, so that process kinetics models are always based on experimental kinetic data. The objective of this research is to obtain kinetic parameters of catalytic decomposition of methane using the catalyst $\mathrm{Ni}-\mathrm{Cu}-\mathrm{Al}$ with composition of 2:1:1 which was prepared by co-precipitation method using natrium carbonate solution presipitan. Experimental kinetic data were taken in the temperature range of $650-750^{\circ} \mathrm{C}$ and pressure of 1 atmosphere. Kinetic data were tested by microkinetic model derived from the catalytic surface reaction mechanism. The most appropriate kinetic model with experimental result is the adsorption stage which shows that consumption of intermediate (reaction surface) faster than the formation of intermediate (adsorption of methane). Kinetic parameters obtained are activation energy of $40.6 \mathrm{~kJ} / \mathrm{mol}$ and pre-exponential factor of $8.625 \times 10^{6}$.
\end{abstract}

Keywords: methane decomposition; hydrogen; carbon nanotubes; coprecipitation, kinetics of reaction

*korespondensi 


\section{Pendahuluan}

Saat ini, karbon nanotube paling banyak dikaji pada kelompok nanokarbon karena strukturnya dan sifat fisiknya yang unik, serta mempunyai nilai tambah yang tinggi karena dapat digunakan sebagai penyimpan hidrogen, nanoscale transistor, flat-panel display, superkapasitor, nanoprobes dan sensor (Daenan dkk., 2003) dan katalis (Zhang, 2004). Produksi nanokarbon secara komersial umumnya menggunakan proses arch-discharge penguapan graphite dan dekomposisi plasma yang menghasilkan karbon berbentuk amorph, tetapi proses ini membutuhkan energi yang sangat besar dan memerlukan pemurnian produk sehingga biaya produksinya sangat mahal dan sulit di scaleup (Li dkk., 2000). Produksi karbon nanotube juga dapat dilakukan melalui reaksi dekomposisi katalitik metana. Reaksi ini bersifat endotermik sehingga membutuhkan temperatur yang tinggi agar terjadi reaksi dekomposisi. Oleh karena itu, digunakan katalis untuk menurunkan energi aktivasi, sehingga konversi maksimum dapat dicapai pada suhu yang lebih rendah.

Dari hasil penelitian sebelumnya (Ermakova dkk., 2000; Purwanto dkk., 2005; Muharam dkk., 2007), katalis multimetal Ni$\mathrm{Cu}-\mathrm{Al}$ merupakan katalis yang paling baik ditinjau dari dengan kualitas produk karbon nanotube maupun yield produk hidrogen serta life time. Nikel merupakan katalis yang paling aktif untuk reaksi dekomposisi katalitik metana, sedangkan promotor $\mathrm{Cu}$ mempunyai peran pencegah sintering dikarenakan partikel $\mathrm{Cu}$ akan menyisip diantara partikel $\mathrm{Ni}$ dan promotor tekstural alumina berperan sebagai stronger-metalinteraction (SMI) yang mencegah terjadinya sintering sehingga diameter partikel Ni tetap kecil.

Pengembangan teknologi produksi karbon nanotube melalui konversi katalitik hidrokarbon akan efisien dan efektif jika didasarkan pada pengetahuan mekanisme nukleasi dan penumbuhan nanotube. Namun, data kinetika dan mekanisme penumbuhan karbon nanotube tidak tersedia dengan lengkap sehingga model kinetika proses selalu didasarkan pada data kinetika eksperimen. Dalam penelitian ini akan dilakukan studi kinetika intrinsik reaksi dekomposisi metana untuk jenis reaktor katalitik menggunakan teknik kopresipitasi dalam preparasi katalis, sedangkan metode yang digunakan adalah metode analisis kinetika mikro dimana penentu laju reaksi bertumpu pada mekanisme reaksi sehingga diharapkan dapat berlaku pada kondisi operasi yang lebih lebar. Reaktor yang digunakan dalam penelitian berjenis packed bed reactor (PBR) dengan tipe aliran diasumsikan plug flow.

\section{Metodologi}

Penelitian ini dibagi menjadi dua bagian, yaitu tahapan preparasi katalis dan tahapan studi kinetika

\subsection{Preparasi Katalis}

Nikel nitrat, tembaga nitrat dan alumina nitrat dicampur dalam $200 \mathrm{~mL}$ air bebas ion kemudian diaduk pada temperatur $50{ }^{\circ} \mathrm{C}$ sampai seluruh padatan tercampur seluruhnya dan ditambahkan presipitat natrium karbonat $1 \mathrm{M}$ hingga mencapai $\mathrm{pH}$ campuran 7. Larutan ini didiamkan selama semalam dan disaring dengan bantuan corong buchner. Wetcake yang didapat dicuci sebanyak empat kali menggunakan air bebas ion dan terakhir menggunakan aseton, lalu dikeringkan menggunakan furnace selama 5 jam pada temperatur $120^{\circ} \mathrm{C}$. terakhir, katalis dikalsinasi menggunakan furnace pada temperatur 250, 500 dan $800{ }^{\circ} \mathrm{C}$, masingmasing selama 1 jam.

\subsection{Uji Kinetika Pendahuluan}

Percobaan pengaruh difusi eksternal pada laju reaksi dilakukan dengan melakukan variasi laju alir umpan pada rasio berat katalis per kecepatan molar (W/F) yang konstan, sampai diperoleh nilai konversi yang konstan, dengan menggunakan kondisi operasi $\mathrm{W} / \mathrm{F}$ sebesar $6,67 \times 10^{-4}$ gram.menit/mL, temperatur 700 ${ }^{\circ} \mathrm{C}$, tekanan $1 \mathrm{~atm}$ dan laju alir metana yang divariasikan adalah 90 sampai dengan 170 $\mathrm{mL} /$ menit. Sedangkan percobaan pengaruh difusi internal pada laju reaksi dilakukan dengan melakukan variasi ukuran diameter partikel katalis pada rasio berat katalis per kecepatan molar (W/F) konstan, laju alir umpan konstan sampai diperoleh nilai konversi yang konstan, dengan menggunakan kondisi operasi W/F 6,67×10-4 gram.menit $/ \mathrm{mL}$, temperatur $700{ }^{\circ} \mathrm{C}$, tekanan 1 atm, laju alir umpan $45 \mathrm{~mL} /$ menit dan variasi diameter partikel $0,125-0,500 \mathrm{~mm}$. 


\subsection{Pengumpulan Data Kinetika}

Data kinetika diambil pada kondisi operasi (laju alir dan diameter katalis) yang didapat dari uji pendahuluan. Selain itu, waktu tinggal $(\mathrm{W} / \mathrm{F})$ juga harus diatur agar konversi yang diperoleh cukup rendah $(<$ $15 \%$ ), sehingga pengolahan datanya dapat didekati dengan teknik perhitungan reaktor diferensial dan efek reaksi balik dapat diabaikan.

Percobaan dilakukan dengan mengalirkan umpan metana ke dalam reaktor yang diset pada tekanan dan temperatur tertentu. Produk gas yang keluar dari reaktor diinjeksikan ke dalam Gas Chromatography (GC) setiap 5 menit selama waktu reaksi 60 menit. Data-data yang diperoleh berupa laju alir umpan, laju alir produk fasa gas, massa produk karbon nanotube, serta luas area peak dari GC, kemudian diolah untuk mendapatkan data kinerja reaksi. Percobaan di atas divariasikan untuk temperatur 650 sampai dengan $750{ }^{\circ} \mathrm{C}$.

\subsection{Pemodelan Kinetika}

Persamaan dekomposisi metana dirumuskan (Snoeck, 1997):

$\mathrm{CH}_{4}(\mathrm{~g}) \rightarrow \mathrm{C}(\mathrm{s})+2 \mathrm{H}_{2}(\mathrm{~g})$

$\Delta \mathrm{H}_{298}=+75 \mathrm{~kJ} / \mathrm{mol}$

Berdasarkan persamaan di atas, maka berikut adalah tahapan reaksi dekomposisi katalitik metana seperti yang terdapat pada literatur (Snoeck, 1997), dengan I adalah notasi untuk inti aktif katalis:

Adsorpsi

$\mathrm{CH}_{4}+\mathrm{I} \Leftrightarrow \mathrm{CH}_{4} \mathrm{I}$

Reaksi Permukaan

$$
\begin{aligned}
& \mathrm{CH}_{4} \mathrm{I}+\mathrm{I} \Leftrightarrow \mathrm{CH}_{3} \mathrm{I}+\mathrm{HI} \\
& \mathrm{CH}_{3} \mathrm{I}+\mathrm{I} \Leftrightarrow \mathrm{CH}_{2} \mathrm{I}+\mathrm{HI} \\
& \mathrm{CH}_{2} \mathrm{I}+\mathrm{I} \Leftrightarrow \mathrm{CHI}+\mathrm{HI} \\
& \mathrm{CHI}+\mathrm{I} \Leftrightarrow \mathrm{CI}+\mathrm{HI}
\end{aligned}
$$

Desorpsi

$$
\mathrm{CI} \Leftrightarrow \mathrm{C}+\mathrm{I}
$$

$$
2 \mathrm{HI} \Leftrightarrow \mathrm{H}_{2}+2 \mathrm{I}
$$

Untuk persamaan di atas, konsentrasi spesies pada fasa gas dapat digantikan oleh tekanan parsial masing-masing, sehingga $\left[\mathrm{CH}_{4}\right]=\mathrm{P}_{\mathrm{CH} 4}$ dan $\left[\mathrm{H}_{2}\right]=\mathrm{P}_{\mathrm{H} 2}$. Penurunan persamaan model kinetika untuk reaksi ini didasarkan pada
Snoeck (1997) untuk masing-masing reaksi sebagai tahap pembatas laju reaksi.

\section{Hasil dan Pembahasan}

Pada penelitian ini menggunakan persamaan desain untuk packed-bed reaktor dan harus memenuhi persamaan:

$\frac{L}{D} \geq 50$

dengan L adalah panjang unggun dan D adalah diameter padatan katalis yang digunakan (Xu dkk., 1989). Persamaan di atas wajib dipenuhi agar aliran yang mengalir di dalam reaktor dapat dianggap aliran plug, dan pada penelitian ini digunakan perbandingan L/D sebesar 51. Parameter kinetik untuk reaksi global dari disosiasi metana diidentifikasi dengan model reaktor sederhana, model reaktor plug-flow. Profil kecepatan fluida berbentuk plug (merata pada posisi radial) dan elemen fluida tercampur sempurna ke arah radial sehingga temperatur fluida merata pada bidang normal terhadap bidang aliran (arah radial) dan tidak terdapat akumulasi reaktan sepanjang reaktor. Untuk memenuhi panjang unggun yang disyaratkan, maka katalis dicampur dengan inert yang tidak berpengaruh terhadap hasil reaksi, dalam penelitian ini digunakan kuarsa bubuk sebagai inert karena memiliki titik leleh yang tinggi $\left(1650^{\circ} \mathrm{C}\right)$ dan merupakan jenis bahan yang sama dengan bahan reaktor.

Katalis dicampur merata dengan inert kuarsa dalam penelitian ini, selain untuk memenuhi persamaan reaktor plug flow, pencampuran merata ini juga bertujuan mengencerkan katalis dan meratakan transfer panas sepanjang unggun. Di dalam reaktor, campuran katalis-inert disangga dengan menggunakan quartz wool di bagian bawah, dan diletakkan juga sejumlah quartz wool di bagian atas.

\subsection{Karakterisasi XRF dan XRD}

Loading yang diharapkan adalah $\mathrm{Ni}: \mathrm{Cu}: \mathrm{Al}=2: 1: 1$. Tabel 1 menyajikan hasil yang didapat dari uji XRF.

Tabel 1. Hasil Uji XRF

\begin{tabular}{ccc} 
Unsur & \%-mol & Rasio \\
\hline $\mathrm{Ni}$ & $52,59 \%$ & 2,9 \\
$\mathrm{Cu}$ & $28,27 \%$ & 1,5 \\
$\mathrm{Al}$ & $18,27 \%$ & 1,0 \\
\hline
\end{tabular}


Komposisi akhir yang didapat ternyata tidak sesuai dengan yang diharapkan. Hal tersebut terjadi karena laju pengendapan masing-masing starting material setelah ditambah dengan prekursor natrium karbonat berbeda, sehingga hal tersebut akan berpengaruh terhadap loading akhir. Peristiwa ini juga dipengaruhi oleh faktor eksternal yang tidak dapat dihindari saat preparasi.

Analisis menggunakan XRD dilakukan secara kualitatif dengan membandingkan pola difraksi (peak) dengan nilai indeks masing-masing komponen yang mempunyai referensi tersendiri dan berbeda untuk masing-masing komponennya. Gambar 1 memperlihatkan pola difraksi XRD untuk katalis $\mathrm{Ni}-\mathrm{Cu}-\mathrm{Al}$ yang digunakan selama penelitian.
Berdasarkan grafik hasil XRD, dengan mencocokkan peak yang dihasilkan dengan pola difraksi reference, maka hasil analisis XRD untuk katalis $\mathrm{Ni}-\mathrm{Cu}$-Al yang digunakan dalam penelitian ini diketahui semua unsur penyusun katalis ini sudah dalam bentuk oksidanya. Hal ini sesuai dengan prinsip metode kopresipitasi yaitu mengontakkan garam logam dengan larutan basa (natrium karbonat) sehingga terjadi pengendapan yang kemudian berubah menjadi bentuk oksida melalui proses pemanasan.

\subsection{Kinetika Pendahuluan}

Gambar 2.a menunjukkan bahwa katalis dengan ukuran diameter 0,125-0,250 mm akan menghasilkan konversi metana $\left(\mathrm{CH}_{4}\right)$ yang konstan, sedangkan katalis yang mempunyai diameter di atas $0,250 \mathrm{~mm}$

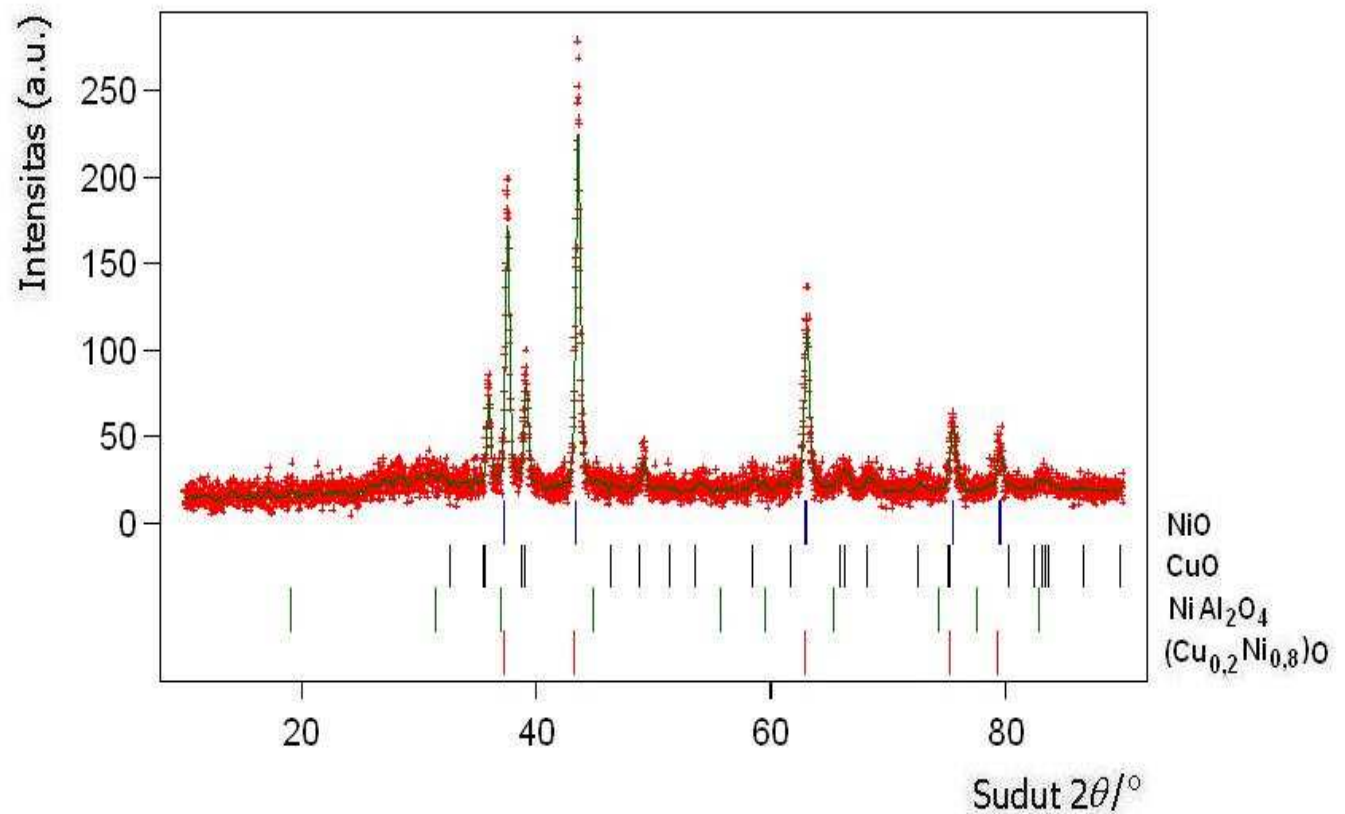

Gambar 1. Pola difraksi XRD katalis Ni-Cu-Al

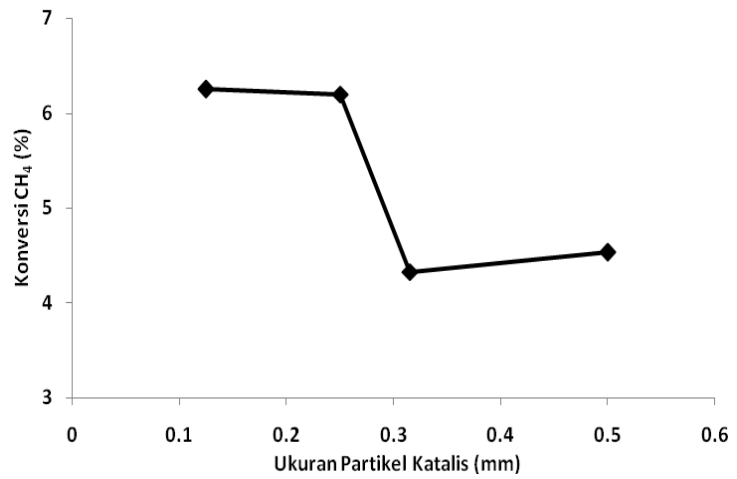

(a)

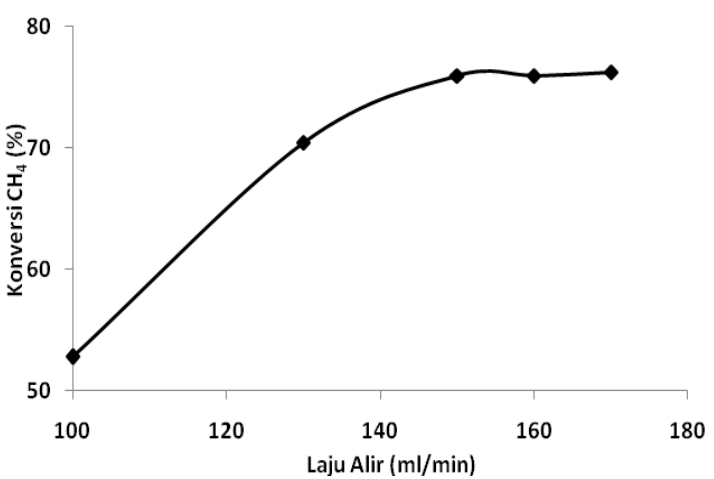

(b)

Gambar 2. Konversi metana sebagai fungsi diameter partikel (a) laju alir (b) 
menyebabkan konversi $\mathrm{CH}_{4}$ menurun. Hal ini menandakan bahwa partikel katalis yang berukuran di atas $0,250 \mathrm{~mm}$ bila direaksikan masih dipengaruhi difusi internal.

Pada uji kinetika pendahuluan ini, terlihat bahwa konversi $\mathrm{CH}_{4}$ relatif konstan pada laju alir umpan di atas $150 \mathrm{~mL} / \mathrm{min}$, dan menandakan daerah tersebut sudah tidak lagi dipengaruhi difusi eksternal. Oleh karena itu, pada penelitian ini digunakan katalis berdiameter $0,125 \mathrm{~mm}$ dan laju alir 160 $\mathrm{mL} / \mathrm{min}$.

\subsection{Pengujian Data Kinetika}

Model persamaan kinetika reaksi dekomposisi katalitik metana dilakukan dengan kinetika mikro. Analisis kinetika mikro diawali dengan merumuskan terlebih dahulu mekanisme reaksi berdasarkan reaksi-reaksi elementer yang terjadi pada permukaan katalis. Model kinetika mikro (Wulan dkk., 2010) yang digunakan dalam penelitian ini adalah model-model yang disusun berdasarkan mekanisme Langmuir sebagaimana yang ditunjukkan pada persamaan (2) sampai (8). Model-model tersebut kemudian diuji keakuratannya dengan data kinetika yang diperoleh dari hasil eksperimental. Pengujian model dilakukan dengan regresi non linear menggunakan analisis solver yang ada pada Microsoft Excel untuk membandingkan keakuratan persamaan laju reaksi hasil eksperimen dan hasil pemodelan. Dalam studi ini, justifikasi model mana yang paling representatif menggambarkan hasil eksperimen, didekati dengan dua metode, yaitu secara statistik dan secara kinetika. Penilaian secara statistik menggunakan dua parameter, yaitu persentase kesalahan (\% error) antara model dengan data di bawah 10 $\%$ dan persentase kevalidan persamaan garis $\left(\mathrm{R}^{2}\right)$ di atas $95 \%$.

Tabel 2 menunjukkan hanya model 4 (Wulan dkk., 2010) saja yang tidak memenuhi batas parameter yang digunakan, sedangkan enam model sisanya memenuhi. Pada tahap ini belum didapatkan satu model akhir yang paling representatif, maka tahap justifikasi model dilanjutkan dengan penilaian dari segi kinetika.

Dari segi kinetika, hanya paramater bernilai positif saja yang dapat dimasukkan dalam persamaan untuk menghitung laju reaksi berdasarkan perhitungan model. Dalam hal ini, maka untuk model 3, model 5 dan model 6, (Wulan dkk., 2010) tidak memenuhi arti fisis yang benar secara kinetika (Slamet, 1996) sehingga untuk selanjutnya yaitu penilaian berdasarkan parameter kinetika hanya melibatkan model 1, model 2 dan model 7 (Wulan dkk., 2010).

Pendekatan secara kinetika dihitung dengan menggunakan persamaan Arhenius untuk mendapatkan nilai energi aktivasi (Ea) dan faktor pra-ekponensial / faktor frekuensi (A). Verifikasi model dilakukan dengan mencocokkan energi aktivasi untuk reaksi serupa yang terdapat pada literatur,sedangkan untuk faktor pra-

Tabel 2. Parameter Kinetika dan Statistika pada Model Persamaan Kinetika Reaksi Dekomposisi Katalitik Metana

\begin{tabular}{cccccccc}
\hline & Model 1 & Model 2 & Model 3 & Model 4 & Model 5 & Model 6 & Model 7 \\
\hline $\mathbf{k M}^{+}$ & 0.0023 & 0.0496 & 0.0111 & 0.0000 & 0.0005 & -4.2505 & 0.4763 \\
kM' $^{\prime}$ & 0.0979 & 0.0301 & -0.0531 & -0.0011 & -0.0778 & 22.6057 & 0.5428 \\
Kr' $^{\prime}$ & 0.0859 & & & & & 22.6057 & 0.5617 \\
Kr" $^{\prime \prime}$ & 0.1106 & 0.0294 & 0.1759 & 0.0071 & 0.0008 & -4.2505 & 0.4789 \\
$\mathbf{K}_{2}$ & 0.0982 & & 0.0211 & 0.0251 & 0.0118 & 9.0000 & 0.7752 \\
$\mathbf{K}_{3}$ & 0.0859 & & -0.0531 & & & & \\
$\mathbf{K}_{4}$ & 0.0859 & & & & & & \\
$\mathbf{K}_{\mathbf{5}}$ & 0.0859 & & & & & & \\
$\mathbf{K C H}_{4}$ & & 0.0500 & 0.0907 & 0.0037 & 0.0013 & 9.0000 & 0.6314 \\
$\mathbf{K C}$ & & & & & & 6.6786 & \\
$\mathbf{K H}$ & 0.1163 & & 0.1945 & 0.0097 & 0.0021 & 22.6057 & 0.4785 \\
\hline Error (\%) & $\mathbf{7 . 4 0 3 6}$ & $\mathbf{7 . 3 8 5 1}$ & $\mathbf{7 . 2 4 0 0}$ & $\mathbf{1 5 . 1 5 4 0}$ & $\mathbf{7 . 5 5 2 2}$ & $\mathbf{7 . 2 2 6 1}$ & $\mathbf{7 . 4 8 6 1}$ \\
$\mathbf{R}^{2}$ & $\mathbf{0 . 9 8 1 9}$ & $\mathbf{0 . 9 8 2 0}$ & $\mathbf{0 . 9 8 3 6}$ & $\mathbf{0 . 7 9 2 3}$ & $\mathbf{0 . 9 8 1 1}$ & $\mathbf{0 . 9 8 3 1}$ & $\mathbf{0 . 9 7 8 7}$ \\
\hline
\end{tabular}


eksponensial yang representatif bernilai kurang dari 1 (Xu dkk., 1989).

Pada penelitian ini, didapat nilai energi aktivasi antara 38 hingga $40 \mathrm{~kJ} / \mathrm{mol}$. Nilai energi aktivasi ini ternyata lebih rendah daripada energi aktivasi pada beberapa jurnal ilmiah untuk jenis reaksi yang sama, yaitu 60-236 kJ/mol (Muradov 2001; Zein dkk., 2004). Ketiga model di atas menghasilkan nilai energi aktivasi yang hampir sama, sehingga juga masih belum mendapatkan satu persamaan kinetika yang representatif. Namun, ternyata persyaratan terakhir dalam penilaian dari segi kinetika, yaitu nilai faktor pra-eksponensial / faktor frekuensi hanya dipenuhi oleh model 1 , sedangkan model 2 dan model 7 tidak memenuhi syarat tersebut. Berdasarkan langkah-langkah verifikasi di atas, baik secara statistik maupun kinetika, maka tahapan yang merupakan tahap pembatas laju reaksi adalah tahapan adsorpsi reaktan (metana) di atas permukaan katalis, dengan persamaan akhir sebagai berikut:

$$
-\mathrm{r}_{\mathrm{CH}_{4}}=8,625 \times 10^{6} \mathrm{e}^{\frac{-40,662}{\mathrm{RT}}} \frac{\left(2,55 \times 10^{-3} \mathrm{P}_{\mathrm{CH}_{4}}-\mathrm{P}_{\mathrm{H}_{2}}{ }^{2}\right)}{\left(1+0,0835 \mathrm{P}_{\mathrm{H}_{2}}{ }^{3 / 2}+0,290 \mathrm{P}_{\mathrm{H}_{2}}{ }^{2}\right)}
$$

Sedangkan bila diinginkan persamaan (10) sebagai fungsi temperatur (Snoeck, 1997), maka perlu diturunkan $\mathrm{k}_{\mathrm{M}}^{+}$dan $\mathrm{k}_{\mathrm{M}}^{-{ }^{-}}$ menggunakan persamaan Arhenius $\left(\mathrm{k}=\mathrm{k}_{\mathrm{o}} \mathrm{e}^{-\mathrm{E}_{\mathrm{a}} / \mathrm{RT}}\right.$ ) sedangkan $\mathrm{K}_{\mathrm{r}}^{\prime}, \mathrm{K}_{\mathrm{r}}^{\prime \prime}, \mathrm{K}_{2}$ dan $\mathrm{K}_{\mathrm{H}}$ diturunkan menggunakan persamaan van't Hoff, $\ln \mathrm{K}=-\frac{\Delta \mathrm{H}^{\circ}}{\mathrm{RT}}+\frac{\Delta \mathrm{S}^{\circ}}{\mathrm{RT}}$, sehingga didapat parameter kinetika :

$$
\mathrm{r}_{\mathrm{C}, \mathrm{M}}=\mathrm{r}_{\mathrm{CH}_{4}}=\frac{\left(\mathrm{k}_{\mathrm{M}}^{+} \mathrm{P}_{\mathrm{CH}_{4}}-\frac{\mathrm{k}_{\mathrm{M}}^{-\prime}}{\mathrm{K}_{\mathrm{r}}^{\prime \prime} \mathrm{K}_{2}} \mathrm{P}_{\mathrm{H}_{2}}^{2}\right)}{\left(1+\frac{1}{\mathrm{~K}_{\mathrm{r}}^{\prime \prime}} \mathrm{P}_{\mathrm{H}_{2}}^{3 / 2}+\frac{1}{\mathrm{~K}_{\mathrm{H}}^{1 / 2} \mathrm{~K}_{2}} \frac{1}{\mathrm{~K}_{\mathrm{r}}^{\prime}} \mathrm{P}_{\mathrm{H}_{2}}^{2}\right)}
$$

$\mathrm{k}_{\mathrm{M}}^{+}=8,113 \exp (-47531 / \mathrm{RT})$

$\mathrm{k}_{\mathrm{M}}^{-{ }^{\prime}}=2,008 \exp (-29831,4 / \mathrm{RT})$

$\mathrm{K}_{\mathrm{r}}^{\prime}=\exp (225,8 / \mathrm{R}) * \exp (-98131,3 / \mathrm{RT})$

$\mathrm{K}_{\mathrm{r}}^{\prime \prime}=\exp (129,9 / \mathrm{R}) \exp (-125113,8 / \mathrm{RT})$

$\mathrm{K}_{\mathrm{H}}=\exp (184,4 / \mathrm{R}) * \exp (-277260 / \mathrm{RT})$

$\mathrm{K}_{\mathrm{H}}=\exp (92,9 / \mathrm{R}) * \exp (92920,6 / \mathrm{RT})$

\section{Kesimpulan}

Komposisi katalis Ni-Cu-Al yang dihasilkan pada penelitian ini bernilai sekitar 2:1:1,3 dari target komposisi 2:1:1. Hasil percobaan pendahuluan menunjukkan bahwa penentuan daerah kinetika yang dapat mengabaikan difusi eksternal dan internal untuk laju alir berada di atas 150 $\mathrm{mL} / \mathrm{min}$ dan diameter partikel di bawah $0,250 \mathrm{~mm}$.

Secara statistika, model persamaan kinetika reaksi dekomposisi katalitik metana dengan reaksi adsorpsi metana pada permukaan katalis sebagai tahap pembatas laju reaksi lebih baik (akurat), dengan parameter kinetika yang diperoleh berupa Energi aktivasi sebesar 40,6 kJ/mol dan faktor pre-eksponensial 8,625 x $10^{6}$. Parameter model kinetika adsorpsi ini sebagai fungsi temperatur, perlu diturunkan $\mathrm{k}_{\mathrm{M}}^{+}$dan $\mathrm{k}_{\mathrm{M}}^{-1}$ menggunakan persamaan Arhenius sedangkan $\mathrm{K}_{\mathrm{r}}^{\prime}, \mathrm{K}_{\mathrm{r}}^{\prime \prime}, \mathrm{K}_{2}$ dan $\mathrm{K}_{\mathrm{H}}$ diturunkan menggunakan persamaan van't Hoff.

\section{Daftar Notasi}

$r=$

$\mathrm{R}=$

$\mathrm{H}=$

$\mathrm{T}=$

$\mathrm{Ea}=$

$\mathrm{A}=$

$\mathrm{k}_{\mathrm{M}}^{+} \operatorname{dan}_{\mathrm{M}}^{-{ }^{-}}=$

laju reaksi $(\mathrm{mol} / \mathrm{g}$ cat.min)

konstanta gas $\quad(8.314$

$\mathrm{kJ} / \mathrm{mol} . \mathrm{K}$ )

entalpi reaksi $(\mathrm{kJ} / \mathrm{mol})$

temperatur $(\mathrm{K})$

energi aktivasi (kJ)

faktor pra-eksponensial

$\mathrm{K}_{\mathrm{r}}^{\prime}, \mathrm{K}_{\mathrm{r}}^{\prime \prime}, \mathrm{K}_{2}$ dan $\mathrm{K}_{\mathrm{H}}=$ koefisen kesetimbangan

\section{Daftar Pustaka}

Daenan M.; de Fouw, R. D.; Hamers, B.; Janssen, P. G. A.; Schouteden, K.; Veld, M. A. J., The Wondrous World of Carbon Nanotubes; Project Report for Philips NAT-Lab and Eindhoven University of Technology: Eindhoven, Februari 2003.

Ermakova, M. A.; Ermakova, D. Y.; Kurshinov, G. G., Effective catalysts for direct cracking of methane to produce hydrogen and filamentous carbon: Part I. Nickel catalysts, Applied Catalysis A: General, 2000, 201(1), 61-71.

Li, Y.; Chen, J.; Qin, Y.; Liu, C., Simultaneous production of hydrogen and nanocarbon from decomposition of methane on a nickel- 
based catalyst, Energy \& Fuels, 2000, 14(16), 1188-1194.

Muharam, Y.; Purwanto, W. W.; Afianty, A., Production of Carbon Nanotubes and Hydrogen from Methane Decomposition in the Reactor With a Structured Catalysts, 14th Regional Symposium on Chemical Engineering, Yogyakarta, 4-5 December 2007.

Muradov, N., Hydrogen via methane decomposition: an application for decarbonization of fossil fuels, International Journal of Hydrogen Energy, 2001, 26(11), 1165-1175.

Purwanto, W. W.; Nasikin, M.; Saputra, E.; Song, L., Decomposition of Methane to Produce Nano Carbon and Hydrogen with $\mathrm{Ni}-\mathrm{Cu}-\mathrm{Al}-\mathrm{Si}$ as the Catalyst, Prosiding Seminar Nasional Rekayasa Kimia dan Proses, Semarang, 27 Juli 2005; hal. 338-344.

Slamet, Studi Kinetika Reaksi Reformasi Metana dengan Karbondioksida Menggunakan Katalis $\mathrm{Ni} / \mathrm{Al}_{2} \mathrm{O}_{3}$, Tesis Magister, Kekhususan Teknologi Gas Universitas Indonesia, Depok 1996.
Snoeck, J. -W.; Froment, G. F.; Fowles, M., Kinetic study of the carbon filament formation by methane cracking on a nickel catalyst, Journal of Catalysis, 1997, 169(1), 250-262.

Wulan, P. P. D. K.; Muharam, Y.; Purwanto, W. W., Kinetics study on catalytic decomposition of methane using parallel flat plate structured catalyst reactor, Industrial \& Engineering Chemistry Research, 2010, 2, 231-241.

Xu, J.; Froment, G. F., Methane steam reforming, methanation and water-gas shift: I. Intrinsic kinetics, AIChE Journal, 1989, 35(1), 88-96.

Zhang, C. Y., Production and Applications of Carbon Nanotubes (CNTs), http://www.ntp.com.cn. L. Shenzhen Nanotech Port Co., 2004 [akses 1 April 2010].

Zein, S. H. S.; Mohamed, A. R.; Sai, P. S. T., Kinetic studies on catalytic decomposition of methane to hydrogen and carbon over $\mathrm{Ni} / \mathrm{TiO}_{2}$ catalyst, Industrial \& Engineering Chemistry Research, 2004, 43(16), 48644870. 